\title{
Effect of a Chemical Treatment Series on the Structure and Mechanical Properties of Abaca Fiber (Musa textilis)
}

\author{
Cyron L. Custodio 1,2,a , Xuan Yang ${ }^{3,4}$, Astrid E. Wilsby ${ }^{3,4}$, Victor F. Waller ${ }^{3,4}$, \\ Ruth R. Aquino ${ }^{1, b}$, Lemmuel L. Tayo ${ }^{1}$, Delia B. Senoro ${ }^{5,6, c}$ \\ and Lars A. Berglund ${ }^{3,4, d}$
}

${ }^{1}$ School of Chemical, Biological, and Materials Engineering and Sciences, Mapúa University, Manila 1002, Philippines

${ }^{2}$ School of Graduate Studies, Mapúa University, Manila 1002, Philippines

${ }^{3}$ Wallenberg Wood Science Center, KTH Royal Institute of Technology, SE-10044 Stockholm, Sweden

${ }^{4}$ Department of Fibre and Polymer Technology, School of Engineering Sciences in Chemistry, Biotechnology and Health, KTH Royal Institute of Technology, SE-10044 Stockholm, Sweden

${ }^{5}$ Office of the International Linkages for Research and Development, Mapúa University, Manila 1002, Philippines

${ }^{6}$ Resiliency and Sustainable Development Center, Yuchengco Innovation Center, Mapúa University, Manila 1002, Philippines

accustodiocyron@gmail.com, brraquino@mapua.edu.ph, 'cdbsenoro@mapua.edu.ph, dblund@kth.se

Keywords: abaca fiber, non-cellulosic components, pectin, cellulose, mechanical properties

\begin{abstract}
This study investigates the relationships between the composition, cell wall microstructure, and mechanical properties of the abaca fiber. Raw abaca fibers have undergone a series of sequential chemical treatments (acetone/methanol, boiling water, EDTA, $\mathrm{HCl}, \mathrm{NaClO}_{2}$, and $\mathrm{NaOH}$ ) to selectively remove certain non-cellulosic components (NCCs) in the fiber, such as waxes, water-soluble fragments, pectin, and lignin in a step-by-step manner. Changes in composition, morphology, and mechanical properties were observed using FTIR spectroscopy and ion chromatography, digital microscope and SEM, and tensile tests, respectively. The raw fiber was composed of $23 \%$ NCCs, $18 \%$ hemicellulose, and 58\% cellulose, and exhibited a 17.4 GPa Young's modulus and a $444 \mathrm{MPa}$ tensile strength. Furthermore, the raw abaca fibers demonstrated a linear tensile graph without yielding, and a planar fracture surface without fiber pull-outs, thus suggesting a highly elastic but brittle nature. At the end of the alkali treatment, the fibrillated fiber was $83 \%$ cellulose, yet the stiffness and strength dropped to $7.3 \mathrm{GPa}$ and $55 \mathrm{MPa}$, respectively, as more components were removed, and microfibril relaxation and realignment have occurred. Load-bearing cellulose and hemicellulose accounted for $42 \%$ and $36 \%$ of the stiffness, respectively, due to $-\mathrm{OH}$ groups capable of hydrogen bonding. $63 \%$ of the strength was due to thenative NCC matrices, which contribute a significant role within the cell wall's load-transfer activities.
\end{abstract}

\section{Introduction}

The search for sustainable yet strong materials has led researchers to utilize abaca fiber as an alternative reinforcement for high strength composites applications [1], due to its mechanical properties that are in par with other natural and synthetic fibers. Although it has been used extensively for composite applications, little information is known about the fibers'cell wall composition, internal microstructure, and property relationships. This work has aimed to determine the abaca fibers' polysaccharide composition and their roles that lead to the bulk fibers' high mechanical properties.

The complex, multicomponent, hierarchical structure of abaca, which closely resembles other plant fibers[2], is illustrated in Fig. 1 which is a natural composite composed of cellulose, hemicellulose, and other non-cellulosic components (NCCs). The highly porous abaca fiber contains 
a hollow center called lumen, surrounded by the cellulose-rich secondary and then primary cell walls. Elementary fibers are bound together through the middle lamella (ML), composed of lignin and pectin. Studies on abaca fiber have been limited to alkali or enzymatic treatments to preserve a fiber with high cellulose fraction, and to induce surface changes. Cai et al. (2015) treated the abaca fibers with increasing $\mathrm{NaOH}$ concentration (0-15 wt\%), and noticed fiber swelling, lumen collapsing, and the instantaneous removal of NCCs, including hemicellulose. The results were lower mechanical properties; Young's modulus from $17 \pm 2.4$ to $12 \pm 3 \mathrm{GPa}$, and tensile strength from $755 \pm 90$ to 840 $\pm 80 \mathrm{MPa}[1]$. Lefeuvre et al. (2015) examined flax fibers under a progressive polysaccharide extraction followed by tensile tests[2]. Flax fibers demonstrated a significant decrease in strength and stiffness upon treatment with EDTA, which delaminated the cell wall interfaces. They also concluded that matrix polysaccharides in the secondary cell wall were responsible for the load transfer, whereas reinforcing polysaccharides aided in the cohesion among cellulose mircofibrils[2].
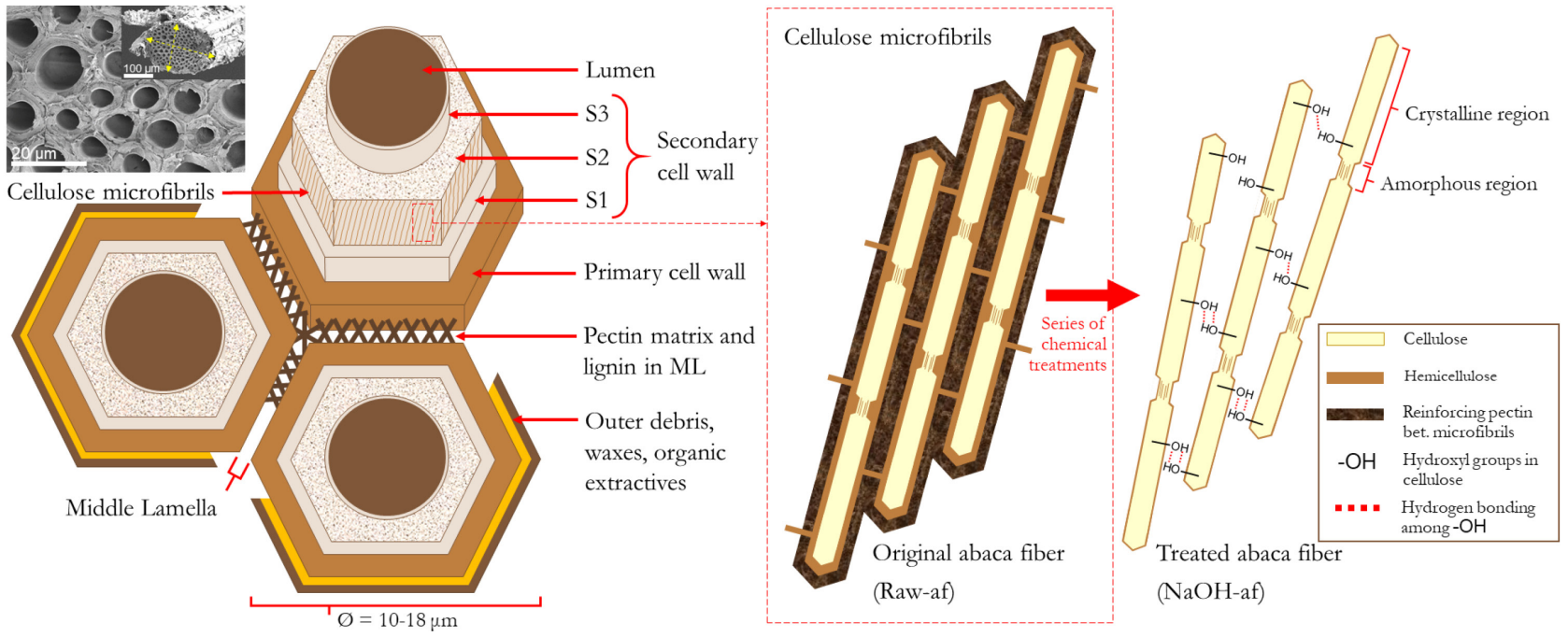

Figure 1. (Left) Hierarchical structure of an abaca fiber cell wall, and (right) a schematic diagram of raw and treated abaca fibers at the cellulose microfibril level.

This research attempts to identify various components present on the abaca fiber and describe their behavior and contribution to the fibers' physicochemical properties. The abaca fibers were subjected to a series of sequential chemical treatments to remove and determine specific polysaccharides. This study also aims to understand the relationship of the fiber composition and cell wall microstructure with the mechanical properties of the abaca fiber. Furthermore, this work presents a comprehensive analysis on the composition, morphology, and mechanical properties of the abaca fiber.

\section{Methodology}

Materials. S2-grade abaca fibers were purchased from the local market in Camarines Sur, Philippines. Methanol and acetone; ethylene-diamine-tetra-acetic acid; sodium hydroxide, hydrochloric acid ( $\geq 37 \%)$, glacial acetic acid, and sodium chlorite $(\geq 80 \%)$; and sodium acetate were purchased from VWR, Acros Organics, Thermo-Fisher Scientific, and Sigma-Aldrich, respectively. The chemicals were at $\geq 99 \%$ purity unless stated, and were used without further purifications. Deionizedwater was used for boiling water, in preparing the solutions, and in the washing steps.

Chemical Treatments. Abaca fibers (af), cut into $10 \mathrm{~cm}$ length, were divided into 7 groups each weighing $2 \mathrm{~g}$. Each group was to reach a certain stage of chemical treatment. Group 1 contained raw, untreated fibers (Raw-af). Group 2 was treated with 1:2 v/v acetone/MeOHsolution at $25^{\circ} \mathrm{C}$ for $1 \mathrm{~h}$ (A/M-af). Group 3 was treated with boiling water for $1 \mathrm{~h}$ (Boiled-af). Group 4 was treated with 0.5 wt $\%$ EDTA at $100^{\circ} \mathrm{C}$ for $1 \mathrm{~h}$ (EDTA-af). Group 5 was treated with $0.02 \mathrm{M} \mathrm{HCl}$ at $100^{\circ} \mathrm{C}$ for $1 \mathrm{~h}$ (HCl-af). Group 6 was treated with $1 \mathrm{wt} \% \mathrm{NaClO}_{2}$ in acetate buffer solution $(4.6 \mathrm{pH})$ at $80^{\circ} \mathrm{C}$ for $4 \mathrm{~h}$ $\left(\mathrm{NaClO}_{2}\right.$-af). Group 7 was treated with $0.5 \mathrm{wt} \% \mathrm{NaOH}$ at $25^{\circ} \mathrm{C}$ for $0.5 \mathrm{~h}$. Each group was washed 
with water at $25^{\circ} \mathrm{C}$ for $0.5 \mathrm{~h}$ prior to the next treatment. Gravimetric mass losses were accounted after each treatment, and shown in Table 1.

\section{Results and Discussion}

Chemical Composition. NCCs lost in each treatment were accounted gravimetrically, and identified via Fourier transform infrared spectroscopy (Spectrum System 2000 FTIR, PerkinElmer) at an average of 32 scans, and a $4 \mathrm{~cm}^{-1}$ resolution, shown in Fig. 2. Amount of insoluble Klason lignin was determined via TAPPI T222 om-02 method. Hemicellulose and cellulose content were determined via carbohydrate analysis (Dionex ICS-3000 ion chromatography system, Thermo Fisher Scientific Inc.). The back calculated results pertaining to the relative polysaccharide fractions for each treated abaca fiber were summarized in Table 1.

Table 1. Relative quantitativecomposition (\%) of abaca fibers.

\begin{tabular}{|c|c|c|c|c|c|c|c|}
\hline \multirow{2}{*}{$\begin{array}{l}\text { Sample } \\
\text { Code }\end{array}$} & \multicolumn{7}{|c|}{ Fiber compositional changes } \\
\hline & Waxes & $\begin{array}{l}\text { Water-soluble } \\
\text { debris }\end{array}$ & $\begin{array}{l}\text { Pectin } \\
\text { in ML }\end{array}$ & $\begin{array}{l}\text { Pectin } \\
\text { bet.microfibrils }\end{array}$ & Lignin & Hemicellulose & Cellulose \\
\hline Raw-af & 8.3 & 0.04 & 2.8 & 4.1 & 8.3 & 18.2 & 58.3 \\
\hline A/M-af & $\mathrm{n} / \mathrm{a}$ & 0.05 & 3.0 & 4.5 & 8.4 & 18.9 & 65.2 \\
\hline Boiled-af & $\mathrm{n} / \mathrm{a}$ & $\mathrm{n} / \mathrm{a}$ & 3.0 & 4.5 & 8.9 & 18.8 & 64.8 \\
\hline EDTA-af & $\mathrm{n} / \mathrm{a}$ & $\mathrm{n} / \mathrm{a}$ & $\mathrm{n} / \mathrm{a}$ & 4.6 & 9.9 & 19.3 & 66.2 \\
\hline $\mathrm{HCl}$-af & $\mathrm{n} / \mathrm{a}$ & $\mathrm{n} / \mathrm{a}$ & $\mathrm{n} / \mathrm{a}$ & $\mathrm{n} / \mathrm{a}$ & 10.5 & 16.0 & 73.5 \\
\hline $\mathrm{NaClO}_{2}$-af & $\mathrm{n} / \mathrm{a}$ & $\mathrm{n} / \mathrm{a}$ & $\mathrm{n} / \mathrm{a}$ & $\mathrm{n} / \mathrm{a}$ & 2.6 & 15.8 & 81.7 \\
\hline $\mathrm{NaOH}-\mathrm{af}$ & $\mathrm{n} / \mathrm{a}$ & $\mathrm{n} / \mathrm{a}$ & $\mathrm{n} / \mathrm{a}$ & $\mathrm{n} / \mathrm{a}$ & 2.7 & 14.5 & 82.8 \\
\hline
\end{tabular}

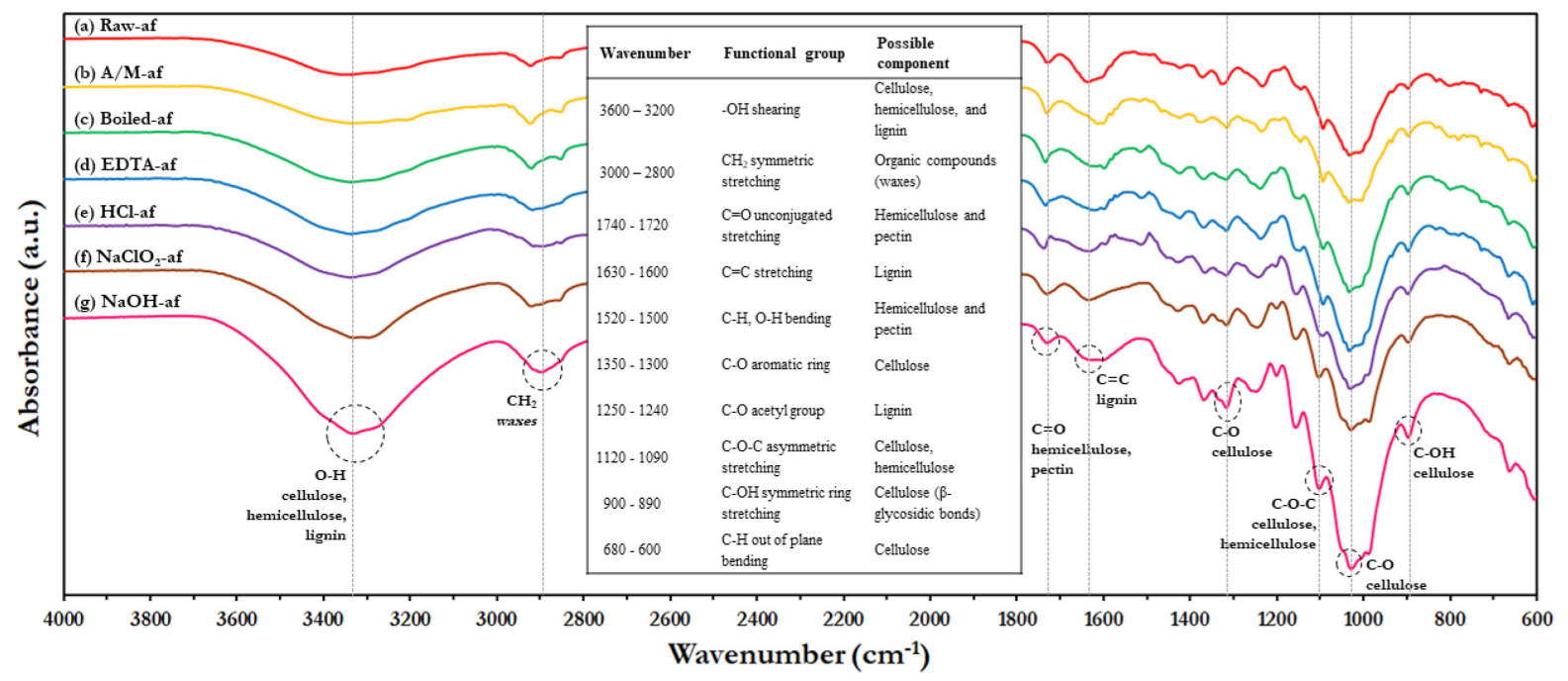

Figure 2. FTIR spectra of the abaca fibers, indicating the removed components after each treatment (inserted: significant wavenumbers and corresponding functional groups and possible components).

Around $8.3 \%$ waxes were removed in $\mathrm{A} / \mathrm{M}$-af, which were correlated by overlapping in the $2900 \mathrm{~cm}^{-1}$ peaks. $0.05 \%$ water-soluble debris were extracted in Boiled-af. 3.0\% matrix pectin in ML were removed in EDTA-af, and was evidenced by the $1520 \mathrm{~cm}^{-1}$ peak disappearance. $4.6 \%$ structuring pectin between microfibrils were removed in $\mathrm{HCl}-\mathrm{af}$, associated with the $1730 \mathrm{~cm}^{-1}$ peak broadening and decreased intensity. All the previous NCCs were removed upon using a strong chlorine-based oxidizing agent. A large drop in the lignin fraction was observed; from $8.2 \%$ down to about 2.6\% lignin was left in $\mathrm{NaClO}_{2}$-af, related to broadening the 1615 and $1245 \mathrm{~cm}^{-1}$ peaks. From $18.2 \%$, approximately $14.5 \%$ hemicellulose was left after the mild alkali treatment in $\mathrm{NaOH}-a f$, and this was correlated to the $1743 \mathrm{~cm}^{-1}$ peak broadening, and $1500 \mathrm{~cm}^{-1}$ increased intensity. Finally, cellulose fractions have been increasing from $58.3 \%$ to $82.8 \%$, as the chemical treatments proceeded, 
since more and more NCCs were removed, leaving cellulose behind. This was verified by the 3350 , 1090,895 , and $680 \mathrm{~cm}^{-1}$ peaks' increased intensity[1,3].

Morphology. Changes color and surface features of the treated fibers were observed using a digital microscope (VHX-7000, Keyence Corporation). Microscopic surface features and cell wall microstructure in the post-tensile cross-sectionwere observed using a field emission scanning electron microscope (Hitachi S-3400). The fibers were sputter-coated (Cressington 208HR) with a thin layer of platinum prior to imaging. The images are shown in Fig. 2.

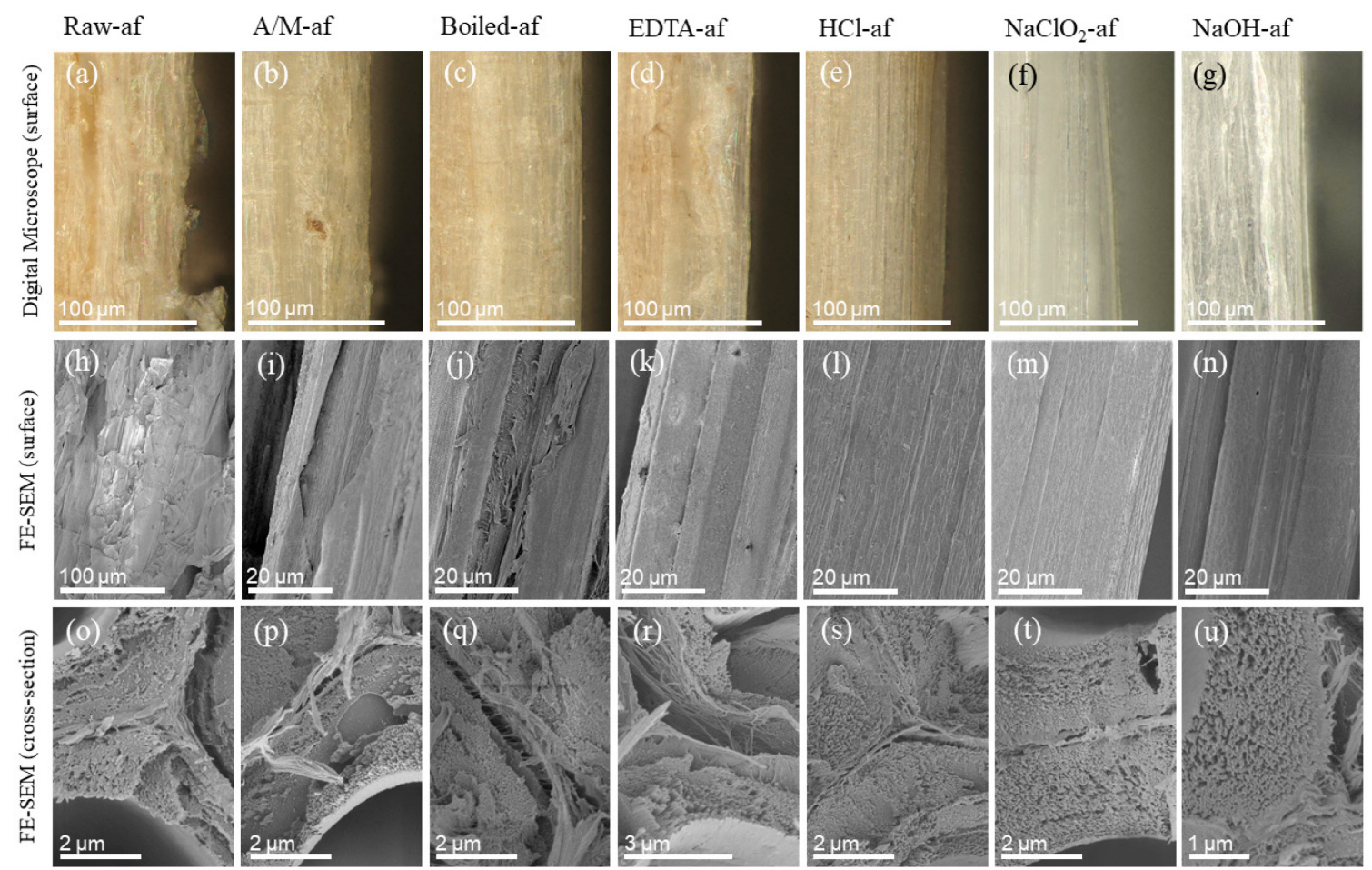

Figure 3. Digital (a-g) and SEM (h-n) images of fiber surface, and SEM (o-u) images of post-tensile fiber cross-section of the treated abaca fibers.

The untreated Raw-af had much surface debris (Fig. 3a, 3h), which acetone/methanol solution removed significantly, including waxes, as seen in $\mathrm{A} / \mathrm{M}$-af (Fig. 3b, 3i). Boiling water initiated layered peeling (Fig. 3j, 3q), while EDTA, which targets pectin matrices[2,3], was able to detach neighboring cell walls by the ML (Fig. 3r). A uniform fiber surface (Fig. 3k) started to develop in EDTA-af. Individual cellulose microfibrils have been liberated and clearly distinguished in HCl-af (Fig. 31), since acid treatment dissolved reinforcing pectin that surrounded each microfibril. The ML also had less bulk at this point, and microfibrils contours were noticeable from the surface. Delignification by chlorine-based bleaching resulted to fiber whitening in $\mathrm{NaClO}_{2}$-af by removing yellowish brown lignin (Fig. 3f)[1]. Well-defined microfibrils were more evident on the surface as well as on the cell wall cross-section (Fig. 3m, 3t). A lesser bulk was found in the ML due to lignin removal. Finally, alkali treatment removed most amorphous hemicelluloses, leaving a crystalline cellulose-rich fiber. A homogenous surface can be seen, and the liberated cellulose microfibrils were protruding outwards the fiber cross-section (Fig. $3 \mathrm{u}$ ).

Mechanical Properties. Tensile tests were carried out to determine the Young's modulus, tensile strength and strain of the treated abaca fibers, based from ASTM D3379-75. The elliptical fibers' major and minor axes were obtained via optical microscope (Olympus). 5 equidistant spots along the fiber axis were measured, through ImageJ, to minimize uncertainty. Tensile tests with 10 trials per fiber group were conducted using an Instron 5944, with a $500 \mathrm{~N}$ static load cell, at a $40 \mathrm{~mm}$ gauge length, and a $0.5 \mathrm{~mm} / \mathrm{min}$ strain rate, in a conditioned room at $23^{\circ} \mathrm{C}$ and $50 \%$ relative humidity. 

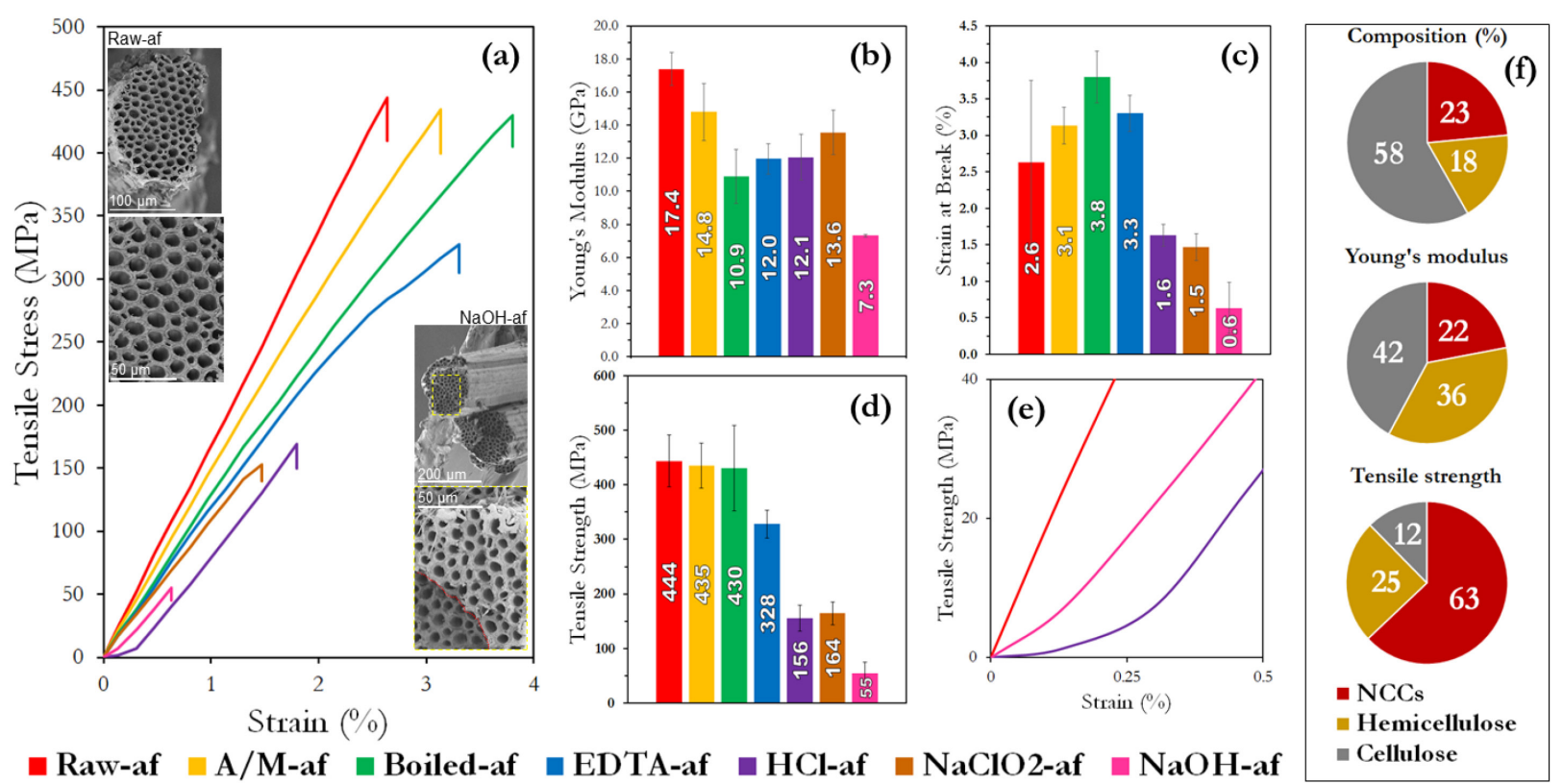

Figure 4. Development of abaca fiber mechanical properties after each chemical treatment: (a) tensile stress-strain graph (insert: Raw-af and $\mathrm{NaOH}$-af cross-section SEM image), (b) Young's modulus, (c) tensile strength, (d) strain at break (error bars were for standard deviation); (e) nonlinear toe regions of $\mathrm{HCl}$-af and $\mathrm{NaOH}$-af; and (f) raw abaca fiber composition, and their corresponding contributions to the Young's modulus and tensile strengths.

The changes in abaca fibers' mechanical properties by removing NCCsare shown in Fig. 4. Raw-af exhibited the highest strength at $444 \mathrm{MPa}$ and stiffness at $17.4 \mathrm{GPa}$, and was characterized with a very linear graph $[1,4]$ without a yield point or plastic deformation (Fig. 4a). Fiber pull-outs were absent in the Raw-af cross-section (Fig. 4a insert), suggesting strong inter-fiber connections and a failure with brittle fracture. Removal of surface waxes for $\mathrm{A} / \mathrm{M}$-af, and water-soluble debris for Boiled-af preserved the strengths, as values remain close at 435 and $430 \mathrm{MPa}$ (Fig. 4d), respectively; however a decreasing trend in modulus was observed(Fig. 4b), down to 14.8 and $10.9 \mathrm{GPa}$, respectively. Moreover, the stress-strain linear behavior was still evident for A/M-af and Boiled-af (Fig. 4a). The removal of NCCs could have initiated the loss of some bulk material and detachment activity in the cell wall(Fig. 3q), allowing for greater mobility and thus longer strains upon failure.

Extracting the matrix pectin in ML for EDTA-af caused a significant drop in strength, at $328 \mathrm{MPa}$ (Fig. 4d), while slightly increasing the modulus at $12 \mathrm{GPa}$ (Fig. 4b). Yield stress was also evident at $\sim 275 \mathrm{MPa}$ (Fig. 4a). Stress transfer between elementary fibers occur at this pectin-rich region. By removing the pectin, delamination occurs (Fig. 3r), load transfer becomes hindered, and elementary fibers are now capable of shearing behavior[3]. Further removal of structuring pectin between microfibrils were carried out via acid hydrolysis using mild $\mathrm{HCl}$, which led to substantial decrease in strength at $156 \mathrm{MPa}$ (Fig. 4d), while stiffness was intact at $12.1 \mathrm{GPa}$ (Fig. 4b). Removing pectin that surround and bind microfibrils together created voids, facilitated the liberation, and increased mobility of these elementary units (Fig. 3s). This accounts for the nonlinear toe region for $\mathrm{HCl}$-af tensile curve (Fig. 4e), which allowed more room for relaxation, sliding, and realignment of the microfibrils upon the applying the tensile load. Delignification removed most lignin located in the ML. At this point the fiber was rid most of its native matrix materials, and was now mostly composed of - $\mathrm{OH}$ rich holocellulose. For $\mathrm{NaClO}_{2}$-af, hydrogen bonding activity accounted for the re-stiffening of the fiber [1] at 13.6 GPa (Fig. 4b), while strength remained at $164 \mathrm{MPa}$ (Fig. 4d). Lastly, mild alkali removed some hemicellulose, leaving the fiber with a high cellulose fraction (Fig. $3 u$ ). Although the $\mathrm{NaOH}-$ af was $\sim 83 \%$ cellulose (Table 1), it exhibited the lowest $55 \mathrm{MPa}$ strength (Fig. 4d) and 7.3 GPa stiffness (Fig. 4b). A similar nonlinear toe region was also observed (Fig. 4e), since alkali is capable of disrupting hydrogen bonds between hemicellulose and cellulose[1,2,5]. This makes the fibers creasy (Fig. 3g), soft, and twisted at the microscopic level, resulting to the dramatic decrease in strength and stiffness. For $\mathrm{NaOH}-a f$, sufficient bonds have been broken, and cellulose 
microfibrils are able to reorientthemselves freely (Fig. 1) during loading [5]. Fracture was also non-uniform (Fig. 4a).

A correlation between the fiber composition and mechanical properties is shown in Fig. 4f. Raw abaca fiberscontained $23 \%$ NCCs, $18 \%$ hemicellulose, and $58 \%$ cellulose. Cellulose was primarily responsible for the Young's moduli[4]. 42\% of the modulus was due to cellulose, and was influenced by microfibril relaxation, shearing, and realignment. Hemicellulose contributed to $36 \%$ of the modulus, due to hydrogen bonding induced stiffness. $63 \%$ of the fiber strength was overwhelmingly due to NCCs $[2,4]$ which were mostly pectin and hemicelluloses. In a multicomponent, hierarchical structure such as abaca, strength is a combination of load-bearing and load-transfer mechanism. A decrease in NCC meant a decrease tensile strength [2]. Although cellulose fraction was highest in $\mathrm{NaOH}-\mathrm{af}$, the absence of binding matrices has limited the cellulosewith its load-bearing action.

\section{Conclusion}

The abaca fiber underwent structural and compositional changes during the sequential chemical treatments. Compositional changeswere quantified and identified via spectroscopic techniques, in which 23\% were NCCs (waxes, pectin, lignin), 18\% hemicellulose, and 58\% cellulose. Morphological development were observed under digital and electron microscopes, and showed delamination under boiling water, EDTA, and mild acid, while cellulose fibrillation were observed via mild acid, bleaching, and alkali treatments. The mechanical properties of abaca fibers were influenced by composition and microstructure changes, as the raw fibers exhibited the highest strength $(444 \mathrm{MPa})$ and stiffness $(17.4 \mathrm{GPa})$. Young's moduli were greatly influenced by the load-bearing microfibrils, and was prone towards relaxation and realignment. Tensile strength was predominantly dependent on $\mathrm{NCCs}^{6}$ load-transfer mechanism. Removing componentsproved to be detrimentalto the mechanical properties. Boiling water treatment is recommended for abaca since it preserved the strength with a slight compromise in stiffness,yet remains inexpensivelyfacile.

\section{Acknowledgment}

We acknowledge the cooperation between Mapúa University, Philippines and KTH Royal Institute of Technology, Sweden with funding from the Linnaeus-Palme Programme of the Swedish International Development Cooperation Agency (Sida). We also acknowledge the resources and facilities provided by the Knut and Alice Wallenberg foundation through the Wallenberg Wood Science Center (WWSC). We also thank Jonas Garemark (WWSC, KTH) for his assistance during the experiments.

\section{References}

[1] Cai, M., Takagi, H., Nakagaito, A. N., Li, Y. \& Waterhouse, G. I. N. Effect of alkali treatment on interfacial bonding in abaca fiber-reinforced composites. Compos. Part A Appl. Sci. Manuf. 90, 589-597 (2016).

[2] Lefeuvre, A. et al. Analysis of the role of the main constitutive polysaccharides in the flax fibre mechanical behaviour. Ind. Crops Prod.76, 1039-1048 (2015).

[3] Sun, R. C., Fang, J. M., Goodwin, A., Lawther, J. M. \& Bolton, A. J. Fractionation and characterization of polysaccharides from abaca fibre. Carbohydr.Polym.37, 351-359 (1998).

[4] Liu, K., Takagi, H. \& Yang, Z. Dependence of tensile properties of abaca fiber fragments and its unidirectional composites on the fragment height in the fiber stem. Compos. Part A Appl. Sci. Manuf. 45, 14-22 (2013).

[5] Oudiani, A. El, Chaabouni, Y., Msahli, S. \&Sakli, F. Crystal transition from cellulose I to cellulose II in $\mathrm{NaOH}$ treated Agave americana L. fibre. Carbohydr.Polym. 86, 1221-1229 (2011). 